\title{
CENTRIFUGAL PATTERNS AND MORPHOLOGICAL VARIATION OF BULL SPERMATOZOA
}

\author{
J. M. O'DONNELL AND D. B. A. SYMONS \\ A.R.C. Institute of Animal Physiology, Babraham, Cambridge
}

(Received 27th August 1969)

\begin{abstract}
Summary. Bull spermatozoa were centrifuged on various density gradients in a zonal centrifuge rotor. Depending on the relative osmolality and viscosity of the gradients, the rates of sedimentation of the spermatozoa varied, but the distribution of the cells in all gradients followed a similar pattern. The distributions showed a single mode and a skewness towards faster-sedimenting cells. The morphology of cell fractions separated by centrifugation was examined by immunofluoresence microscopy. A significantly greater proportion of cells had lost the acrosome in faster, as compared with slower, fractions. Acrosome degeneration and loss are known to be indicators of cell senescence. Therefore, it is considered that centrifugation of bull spermatozoa on density gradients results in a distribution which reflects the age of the cells. The natural heterogeneity in samples of ejaculated spermatozoa was reduced by treatment with detergent. Detergent treatment of spermatozoa altered the centrifugation pattern to a near normal distribution.
\end{abstract}

\section{INTRODUCTION}

Exploitable differences in phenotype of mammalian spermatozoa, attributable to genotypic differences, have been sought by a variety of methods, usually with the object of separating $\mathrm{X}$ - and Y-chromosome-bearing cells. Such experiments have commonly employed sedimentation of spermatozoa by gravity (Bhattacharya, 1958, 1962; Bhattacharya, Bangham, Cro, Keynes \& Rowson, 1966; Schilling, 1966; Bedford \& Bibeau, 1967) or by centrifugation (Lindahl, 1958; Beatty, 1964, 1969; Benedict, Schumaker \& Davies, 1967). Subsequent insemination with sedimented fractions of bull and rabbit spermatozoa has not significantly influenced the normal sex ratio of offspring in a reproducible manner, neither has a characteristic pattern of sedimentation for a particular population of cells yet emerged.

Recently Beatty (1969), although not finding any influence of buoyant density of spermatozoa on three simple Mendelian factors in rabbits, did find an apparent influence of density class on birth weight. Beatty concluded that this was highly provisional evidence of a possible 'haploid effect' for birth weight, but that any influence on sex ratio was unlikely.

Benedict et al. (1967) centrifuged spermatozoa to equilibrium on density 
gradients. Bull spermatozoa fractionated into high and low density moieties, the high density fraction showing two distinct bands. Cell dimensions and structure, determined by phase-contrast microscopy, did not differ significantly between the fractions, the differences between high and low density being attributed to differences in cell permeability. However, the gradient media employed exerted large osmotic effects on the cells at high concentration.

The present experiments were designed to establish the sedimentation pattern of bull spermatozoa under conditions as near to ideal as possible and to relate morphological characteristics of individual cells to their sedimentation rate. The centrifugation system was a zonal rotor of the type described by Anderson (1966) which is considered to have significant advantages over other centrifugation methods. Three gradient materials were used, providing ranges of toxicity, osmolality and viscosity.

Acrosomal deterioration has been shown to be correlated with senescence of spermatozoa (Saacke \& Marshall, 1968). This morphological change has been taken in the present study as an index of cell integrity in fractions of sedimented spermatozoa. Differentiation of the acrosome was achieved with immunofluoresence based on the natural antibody to spermatozoa present in the serum of many mammalian species which reacts specifically with the acrosome (Beck, Edwards \& Young, 1962; Symons, 1968; Johnson, 1968). A preliminary account of centrifugation experiments has been published (O'Donnell, 1969a).

\section{MATERIALS AND METHODS}

\section{Density gradient centrifugation of spermatozoa}

Semen was obtained from two Jersey bulls, and one ejaculate used in each centrifugation. Semen samples were cooled slowly to $20^{\circ} \mathrm{C}$ or to $0^{\circ} \mathrm{C}$.

Each dense component was dissolved in an artificial bull seminal plasma, ABSP (O'Donnell, 1969b). Three dense components were evaluated, sucrose (A.R. Grade), a dextran, Ficoll (Pharmacia) and polyvinylpyrrolidone, PVP $(\mathrm{BDH})$. Gradients were generated by allowing the dense solution to feed by gravity into a round-bottomed flask initially filled with ABSP and incorporating a vibro-mixer (Chemap, AG); simultaneously the gradient was withdrawn and pumped into the rotor which was spinning at $300 \mathrm{rev} / \mathrm{min}$. In this way, a gradient was generated in which density increased exponentially with volume but was nearly linear with radius in the rotor. The rotor (A XII, MSE) was spinning in a Mistral centrifuge with illumination to facilitate the inspection of contents (Pl. 1, Fig. 1). A total gradient volume of I litre was followed by a 'cushion' of $50 \% \mathrm{v} / \mathrm{v}$ glycerol: water.

Following the introduction of gradient and cushion, the semen sample was layered on to the inner edge of the gradient by syringe and adjusted to starting position. The sample was followed by a further $100 \mathrm{ml}$ of ABSP as 'overlay'. The rotor speed was adjusted as desired and centrifugation continued to termination. At termination, the rotor speed was reduced to $300 \mathrm{rev} / \mathrm{min}$ and the gradient removed by pumping more cushion solution into the rotor. The gradient was fractionated as it emerged from the spinning rotor.

Densities of gradient fractions were measured pycnometrically, viscosity was 
determined with a Hoeppler viscosimeter and osmolality by means of a cryoscopic osmometer (Fiske). Concentrated solutions of Ficoll or PVP could not be measured in the Fiske osmometer, and the osmolality was calculated from measurements on more dilute solutions.

\section{Morphological examination of centrifuged spermatozoa}

Spermatozoa in the fractions were counted electronically (O'Donnell, 1969c). Ten drops (approx. $0.3 \mathrm{ml}$ ) of selected fractions of centrifuged spermatozoa in Ficoll gradients were loaded in each bucket of a cytocentrifuge (Shandon) and centrifuged on to microscope slides at $500 \mathrm{rev} / \mathrm{min}$ for $10 \mathrm{~min}$, $0.1 \mathrm{ml}$ of $0.154 \mathrm{M}-\mathrm{NaCl}$ was added to the buckets and the centrifugation repeated to wash residual Ficoll from the slides. Preparations were air-dried, fixed for $10 \mathrm{~min}$ in $95 \%$ ethanol at $20^{\circ} \mathrm{C}$ and air-dried again before storing at $-20^{\circ} \mathrm{C}$. Spermatozoa were usually examined by immunofluorescence within $48 \mathrm{hr}$ of preparation.

The indirect immunofluorescence technique was used. Normal rabbit serum, heated for $30 \mathrm{~min}$ at $56^{\circ} \mathrm{C}$ and diluted $\times 2$ with phosphate-buffered saline (pH 7.0), was layered over the specimen for $30 \mathrm{~min}$ at $20^{\circ} \mathrm{C}$ in a humid chamber. After thorough washing in buffered saline, goat anti-rabbit globulin conjugated with fluorescein isothiocyanate (Difco) was applied for $30 \mathrm{~min}$. Preparations were then further washed, mounted in buffered glycerol $(\mathrm{pH} 7 \cdot 0)$ and examined with a Zeiss photomicroscope, fitted with HBO 200 burner, UG1/3.0-mm exciter filter, dark-field illumination and Zeiss 47 or 50 secondary filter.

Intact spermatozoa exhibited bright fluorescence confined to a clearly delineated acrosome, while progressive disruption of the acrosome could be observed as increasingly irregular fluorescence. Loss of the acrosome was indicated by absence of fluorescence from the sperm head. Only those cells which lacked fluorescence were scored as 'acrosome-less'.

\section{Detergent treatment of spermatozoa}

Treatment of spermatozoa with detergents is known to increase the permeability of, and ultimately detach, the plasma membrane of the cells (KoefoedJohnsen \& Mann, 1954). Spermatozoa which had been packed by centrifugation were resuspended with ABSP containing $0.1 \%$ Triton X100 (Rohm and Haas) for $1 \mathrm{hr}$ at $20^{\circ} \mathrm{C}$. Triton-treated cells were centrifuged as above. The effects of detergent were assessed by dark-field and immunofluorescence microscopy.

\section{RESULTS}

Centrifugation patterns on different density-gradients

The centrifugation behaviour of spermatozoa on density-gradients incorporating sucrose, PVP and Ficoll was compared by standardizing all other conditions of centrifugation. Each run was performed at $1000 \mathrm{rev} / \mathrm{min}$ for 90 $\min$ at $0^{\circ} \mathrm{C}$. For each type of dense constituent, the gradients were of the same profile and the volume in the system was constant.

The gradients differed as to specific gravity, osmolality and viscosity. The 
osmotic increment in sucrose gradients was many times greater than in PVP or Ficoll, while viscosities of the latter two gradients increased much more rapidly than did sucrose gradients. The results of several centrifugations in three types of gradient are summarized in Table 1. In sucrose, the cells reached

TABLE 1

PROPERTIES OF DENSITY GRADIENTS AT THE MODES OF SPERM DISTRIBUTION

\begin{tabular}{l|c|c|c}
\hline $\begin{array}{c}\text { Gradient } \\
\text { dense } \\
\text { component }\end{array}$ & $\begin{array}{c}\text { Sp.gr. } \\
(\text { Mean } \pm S . E .)\end{array}$ & $\begin{array}{c}\text { Osmolality } \\
(\text { m-osmoles })\end{array}$ & $\begin{array}{c}\text { Viscosity } \\
(\text { centipoises })\end{array}$ \\
\hline Sucrose & $1 \cdot 116 \pm 0 \cdot 004(4)^{*}$ & $>1000$ & 4 \\
PVP & $1 \cdot 027 \pm 0.002(4)$ & 348 & 5 \\
Ficoll & $1 \cdot 043 \pm 0.001(6)$ & 325 & 6 \\
\hline
\end{tabular}

All runs at $1000 \mathrm{rev} / \mathrm{min}$ for $90 \mathrm{~min}$ at $0^{\circ} \mathrm{C}$. Measurement of gradient properties at $20 \pm 2^{\circ} \mathrm{C}$.

* Number of runs in parentheses.

a much greater specific gravity than in the other two gradients, the difference between these being relatively much smaller. The reasons for cells sedimenting faster in sucrose than in PVP or Ficoll were probably a combination of lower viscosity and higher osmolality for a given specific gravity in the gradient. On the same basis, the slight difference in position on Ficoll and PVP gradients may be attributed to the relatively greater increment in viscosity in PVP.

Although the absolute specific gravity positions attained by centrifuging spermatozoa in the gradients differed, the pattern of cell distribution in the three types of gradient was markedly similar. Text-fig. 1 shows the distribution of cells in three typical experiments. These distributions showed a single mode only and in each case they are skewed strongly in the direction of faster moving cells. This feature was observed in centrifugations under all conditions.

\section{Variations in morphology of centrifuged spermatozoa}

Since the pattern of the distribution of cells was constant in different gradients and under different conditions of time and speed, it was possible to investigate the factors governing the initial rate of sedimentation of the cells. In this way, any deleterious effects of the centrifugation process itself, which might distort or amplify differentiation of the cells, would be minimal. The conditions chosen for these runs were as mild as possible; the cells were cooled to $20^{\circ} \mathrm{C}$, and centrifuged in a Ficoll gradient for $45 \mathrm{~min}$ at $700 \mathrm{rev} / \mathrm{min}$. This procedure was sufficient to generate the characteristic distribution of cells in the gradient.

Table 2 shows the results of four experiments in which the loss of acrosomes was counted. In each case the fast fraction had a greater proportional loss of acrosomes from the spermatozoa than did the corresponding slower fractions. This relationship applied over a fairly wide range of values. The mean value for percentage loss from the fast fractions $(20 \cdot 2 \pm 2.5)$ was significantly higher than that for slow fractions $(8 \cdot 8 \pm 2 \cdot 2), P<0.025$.

Morphologically, the cells of the slow fractions were very little altered from the control preparations. Their acrosomes were generally intact, adherent to 

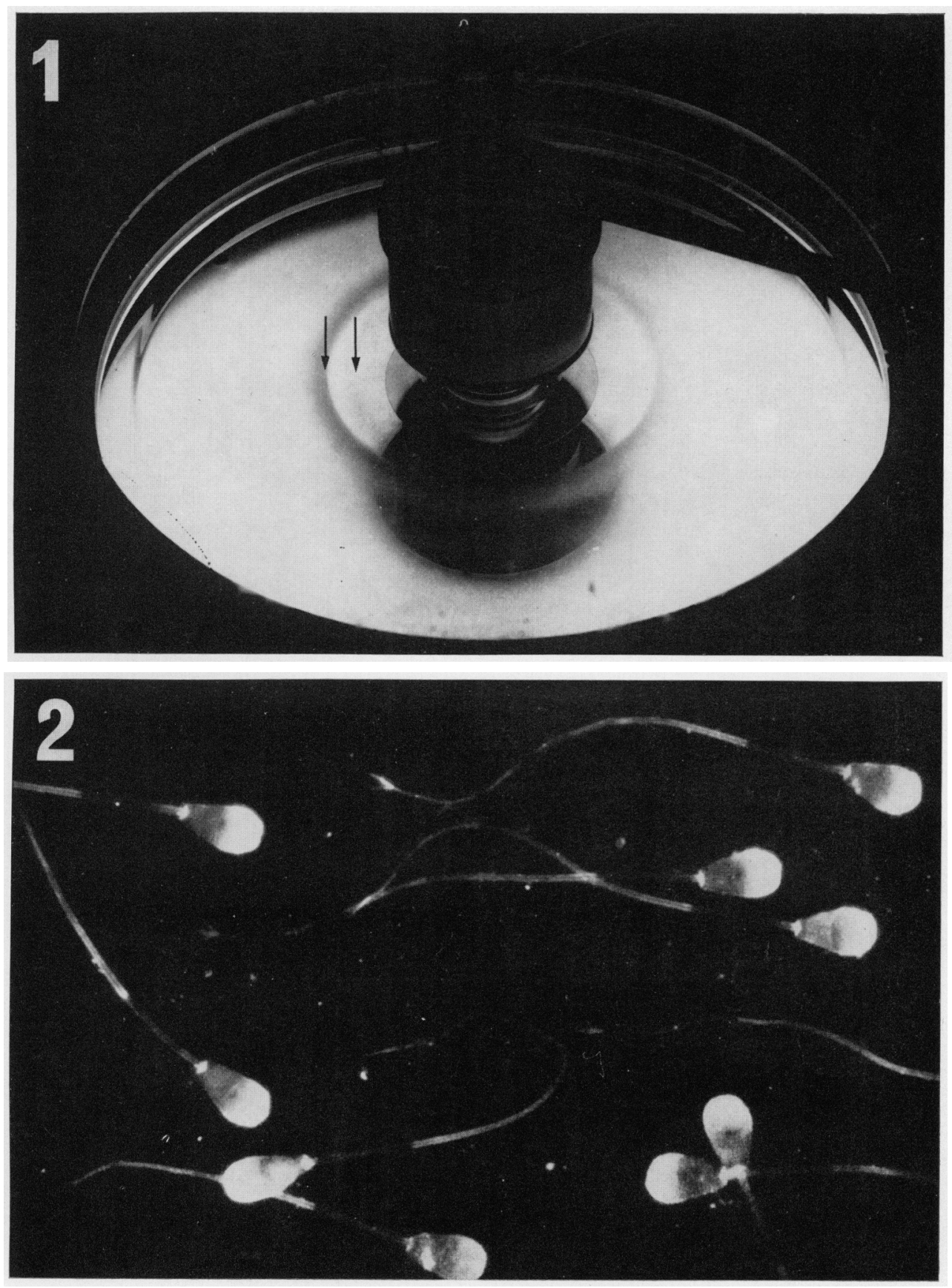

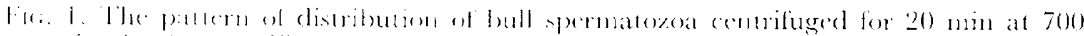

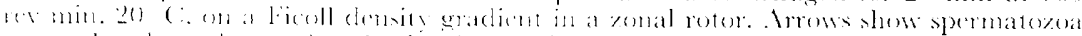

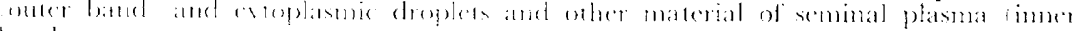
land

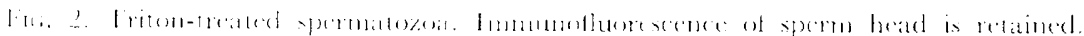

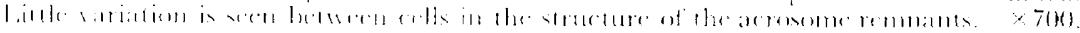



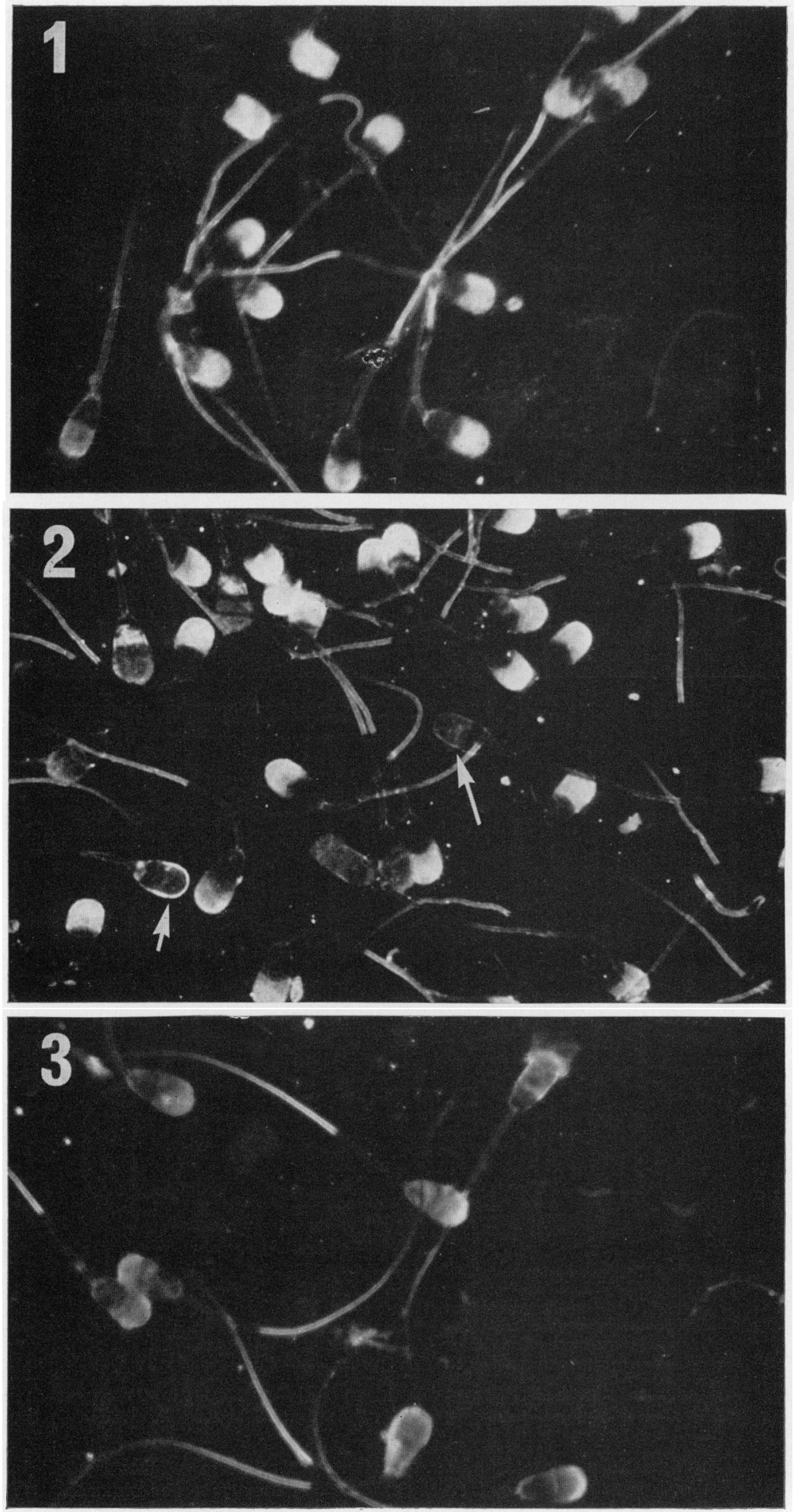


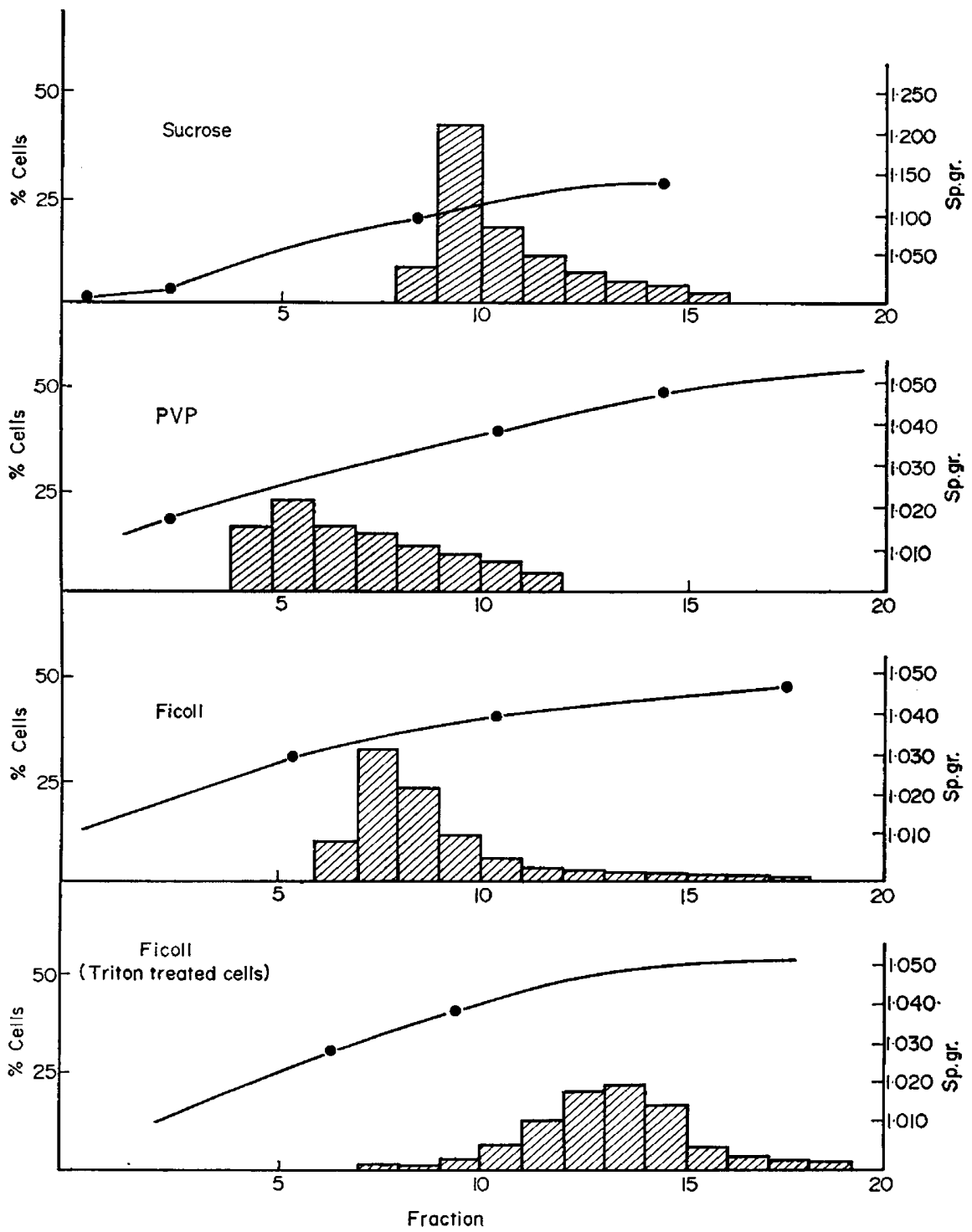

Text-Fig. 1. Distribution of spermatozoa in density gradients. Conditions of centrifugation: $1000 \mathrm{rev} / \mathrm{min}$ for $90 \mathrm{~min}$ at $0^{\circ} \mathrm{C}$, except for the Triton-treated cells, which were spun at $700 \mathrm{rev} / \mathrm{min}$ for $40 \mathrm{~min}$ at $20^{\circ} \mathrm{C}$. Note different specific gravity range in sucrose density gradient.

\section{EXPLANATION OF PLATE 2}

FIg. I. Slow fraction. The majority of spermatozoa have a brightly fluorescent acrosome. $\times 530$.

Fig. 2. Middle fraction. A large proportion of spermatozoa have a brightly fluorescent acrosome. Spermatozoon at lower left (arrowed) has fluorescence confined to the 'apical ridge'. Spermatozoon at centre has lost all fluorescence. These cells illustrate two stages of acrosome degeneration. $\times 530$.

Fig. 3. Fast fraction. Although many of these cells retain the acrosome, fluorescence of the sperm head is much weaker than in slower fractions. Cell at top right is shedding the acrosome membrane. $\times 530$. 
the sperm head although a little expanded and fluorescence was bright over the whole surface of the acrosome (Pl. 2, Fig. 1). Samples of the middle fractions contained more spermatozoa with degenerating acrosomes, the various stages of disruption becoming apparent in these preparations (Pl. 2, Fig. 2). In the fast fractions, the fluorescence of the preparations as a whole was much weaker (PI. 2, Fig. 3). Even those cells which retained an apparently unmodified acrosome were rarely brightly fluorescent. As in the middle fractions, all stages of acrosome disruption could be found.

TABLE 2

PERGENTAGE AGROSOME LOSS FROM FRACTIONS OF GENTRIFUGED BULL SPERMATOZOA

\begin{tabular}{c|c|c|c}
\hline \multicolumn{1}{c|}{ Slow } & Middle & Fast & Control \\
\cline { 1 - 3 } $11.2(349)$ & - & $24.9(365)$ & -7 \\
$14.9(525)$ & - & $25.5(530)$ & $3.0(303)$ \\
$6.9(619)$ & $11.3(549)$ & $17.0(560)$ & $1.8(637)$ \\
$2.2(535)$ & $8.9(549)$ & $13.5(690)$ & $2 \cdot 7(511)$ \\
\hline$* 8.8 \pm 2 \cdot 2$ & $10 \cdot 1 \pm 0.9$ & $20.2 \pm 2.5$ & $2 \cdot 5 \pm 0.3$ \\
\hline
\end{tabular}

Numbers in parentheses indicate the total number of cells counted.

Spermatozoa fractionated on ABSP : Ficoll gradients at $700 \mathrm{rev} / \mathrm{min}$ for $45 \mathrm{~min}$ at $20^{\circ} \mathrm{C}$.

$*$ Mean \pm S.E.

\section{Detergent-treated spermatozoa}

The aim of detergent treatment was to reduce all cells to a uniform morphological state with respect to their membrane integrity and hence to reduce the heterogeneity of the cell population. The morphological variation between cells observed in untreated samples (see Plate 2) was greatly reduced. Spermatozoa apparently lacked the outer acrosomal membrane and the fibres at the end piece were separated and splayed (PI. 1, Fig. 2). These effects signify loss of the plasma membrane.

When centrifuged in the same manner as untreated cells, detergent-treated spermatozoa showed a significantly different centrifugation pattern. The skewness towards faster moving cells was absent, the cells sedimenting in a near normal distribution (Text-fig. 1). These cells, as a population, sedimented relatively faster than untreated spermatozoa.

\section{DISCUSSION}

These results show that when bull spermatozoa are centrifuged on density gradients which are close to physiological in terms of $\mathrm{pH}$, osmolality, viscosity and ionic strength the sedimentation behaviour of the cells is not unlike that of other cell populations which have been investigated, e.g. mammalian erythrocytes. The experiments with sucrose density-gradients indicated that deviations from physiological conditions could give rise to misleading results, primarily as a consequence of osmotic effects. Provided observations are confined to the initial rate of centrifugation, the cells show only a single mode in 
sedimentation rate. In similar experiments with mammalian red cells, it has been observed that the older cells are more rapidly centrifuged than the younger (Prankerd, 1958; Leif \& Vinograd, 1964). The volume distribution of bull spermatozoa, measured electronically, shows a similar skewness to that observed in red cells (Weed \& Bowdler, 1967; O'Donnell, 1969c).

In the absence of a direct labelling technique for the estimation of 'age' of bull spermatozoa, use has been made of morphological criteria associated with ageing in vitro. Visible modifications of the acrosome structure are believed to be initiated either immediately before cell death or post mortem (Hancock, 1966). The sequence of degenerative changes affecting the acrosome of bull spermatozoa which is associated with loss of cell viability has been described in light and electron microscopy studies by Saacke \& Marshall (1968). Of particular relevance to the present study is their demonstration of the initial breakdown of the outer acrosomal membrane with consequent exposure of the acrosomal ground substance. In later stages, the ground substance is dispersed and all membranes are lost.

Soluble components of the bull sperm acrosome are readily transferred to the external medium, for example hyaluronidase (Masaki \& Hartree, 1962). Such transfer occurs even while the acrosome remains attached to the spermatozoa. Thus, breakdown of the acrosome to the degree recorded in the present study undoubtedly signifies acceleration of the dispersal of soluble components from the acrosome. The identity of the acrosomal component against which the natural antibody of serum reacts is not yet known. Since the serum reaction, determined by immunofluorescence, weakens as the acrosome deteriorates, it seems probable that the reaction is against a soluble component which is dispersed as the cell ages. Hence, the fluorescence of spermatozoa from the faster sedimenting fractions which still retained the acrosome was much weaker than that of cells from slower fractions. Swelling of the acrosome before its detachment is obviously not an osmotic effect involving an increase in the degree of hydration of the cells, since this would involve a decrease rather than an increase in sedimentation velocity. The swelling associated with loss of the acrosome occurs in cells in which the cell membrane is no longer an effective semipermeable barrier to solutes. That such swollen cells move towards the leading edge of the centrifuged cell population must be interpreted as evidence that the more aged cells are denser than those which still show morphological integrity.

In these experiments, it has been shown that the incidence of progressive acrosome degeneration increases with increasing sedimentation rate and hence, by inference, that the faster fractions contain a greater proportion of senile cells. In fertility trials of sedimented spermatozoa, it would therefore be expected that the faster fractions would fertilize less successfully than slower fractions. The results of Benedict et al. (1967) support this. Detergent treatment which greatly reduces variation in a cell population by reducing all cells to a common 'membrane-less' state, has been shown to alter the sedimentation behaviour of bull spermatozoa in two respects. Firstly, the characteristic skewness in distribution of untreated cells is abolished while, secondly, the overall rate of sedimentation of the sperm population is increased. These results indicate that the 
variability of sedimentation behaviour of untreated cells is an expression of variation between spermatozoa which is confined to their membrane structure and integrity.

\section{ACKNOWLEDGMENTS}

We wish to thank Dr R. D. Keynes, F.R.s., for his interest in this work and for his helpful criticism of the manuscript. Technical assistance from M. Rennie, D. Gadsby and Miss B. Hick is gratefully acknowledged.

\section{REFERENCES}

Anderson, N. G. (1966) The development of zonal centrifuges and ancillary systems for tissue fractionation and analysis. Natn. Cancer Inst. Monogr. 21, Washington.

Beatty, R. A. (1964) Density gradient media for mammalian spermatozoa. Proc. Vth int. Congr. Anim. Reprod., Trento, p. 276.

Beatty, R. A. (1969) Genetic content and buoyant density of rabbit spermatozoa. F. Reprod. Fert. 19, 379.

Beck, J. S., Edwards, R. G. \& Young, M. R. (1962) Immune fluorescence technique and the isoantigenicity of mammalian spermatozoa. F. Reprod. Fert. 4, 103.

Bedford, J. M. \& Bibeau, A. M. (1967) Failure of sperm sedimentation to influence the sex ratio of rabbits. F. Reprod. Fert. 14, 167.

Benedict, R. G., Schumaker, V. N. \& Davies, R. E. (1967) The buoyant density of bovine and rabbit spermatozoa. 7. Reprod. Fert. 13, 237.

Bhattacharya, B. G. (1958) Sex control in mammals. Z. Tierzücht. ZüchtBiol. 72, 250.

Bhattacharya, B. C. (1962) Die verschiedene Sedimentationsgeswindigheit der X-and Y-spermien und die Frage der willkurlichen Geslechtsbestimmung. Z. wiss. Zool. 166, 203.

Bhattacharya, B. C., Bangham, A. D., Cro, R. J., Keynes, R. D. \& Rowson, L. E. A. (1966) An attempt to predetermine sex of calves by artificial insemination with spermatozoa separated by sedimentation. Nature, Lond. 211, 863.

HANcock, J. L. (1966) The ultra-structure of mammalian spermatozoa. In: Advances in Reproductive Physiology, Vol. 1, p. 125. Ed. Anne McLaren. Logos Press, London.

JoHnson, M. H. (1968) Characterization of a natural antibody in normal guinea-pig serum reacting with homologous spermatozoa. F. Reprod. Fert. 16, 503.

Koefoed-Johnsen, H. H. \& Mann, T. (1954) Effect of surface-active agents with special reference to oxidation of succinate by spermatozoa. Biochem. F. 57, 406.

LeIF, R. C. \& Vinograd, J. (1964) The distribution of buoyant density of human erythrocytes in bovine albumin solution. Proc. natn. Acad. Sci. U.S.A. 51, 520.

LiNDAHL, P. E. (1958) Separation of bull spermatozoa carrying X-and Y-chromosomes by counterstreaming centrifugation. Nature, Lond. 181, 784.

Masaki, J. \& HARTREe, E. F. (1962) Distribution of metabolic activity, phospholipid and hyaluronidase between heads and tails of bull spermatozoa. Biochem. F. 84, 347 .

O'DoNNELL, J. M. (1969a) Zonal centrifugation of bovine spermatozoa on density gradients. F. Physiol., Lond. 200, 15P.

O'DoNNELL, J. M. (1969b) Intracellular levels of sodium and potassium in bull spermatozoa in relation to cell metabolism. F. Reprod, Fert. 19, 207.

O'DonNell, J. M. (1969c) Electronic counting and sizing of mammalian spermatozoa and cytoplasmic droplets. F. Reprod. Fert. 19, 263.

Prankerd, T. A. (1958) The ageing of red cells. F. Physiol., Lond. 143, 325.

SAAcke, R. G. \& Marshall, C. E. (1968) Observations on the acrosomal cap of fixed and unfixed bovine spermatozoa. 7. Reprod. Fert. 16, 511.

Schilling, E. (1966) Experiments in sedimentation and centrifugation of bull spermatozoa and the sex ratio of born calves. F. Reprod. Fert. 11, 469.

Symons, D. B. A. (1968) Immunofluorescent study of the antigenicity of mammalian spermatozoa. Ph.D. thesis, University of London.

WEED, R. I. \& BowDLER, A. J. (1967) The influence of haemoglobin concentration on the distribution pattern of the volumes of human erythrocytes. Blood, 29, 297. 